\title{
SERVICE ROBOTS IN HOSPITALS: NEW PERSPECTIVES ON NICHE EVOLUTION AND TECHNOLOGY AFFORDANCES
}

\author{
Tobias Mettler $^{1^{*}}$, Michaela Sprenger ${ }^{2}$, Robert Winter ${ }^{2}$ \\ ${ }^{1}$ University of Lausanne, Swiss Graduate School of Public Administration, Rue de la Mouline 28, \\ CH-1022 Chavannes-près-Renens, Switzerland, \\ ${ }^{2}$ University of St. Gallen, Institute of Information Management, Müller-Friedberg-Strasse 8, \\ CH-9000 St. Gallen, Switzerland \\ *Corresponding author: tobias.mettler@unil.ch \\ Citation: Mettler, T., Sprenger, M. \& Winter, R. European Journal of Information Systems (2017). \\ doi:10.1057/s41303-017-0046-1
}

Abstract: Changing demands in society and the limited capabilities of health systems have paved the way for robots to move out of industrial contexts and enter more human-centered environments such as healthcare. We explore the shared beliefs and concerns of health workers on the introduction of autonomously operating service robots in hospitals or professional care facilities. By means of Qmethodology, a mixed research approach specifically designed for studying subjective thought patterns, we identify five potential end-user niches, each of which perceive different affordances and outcomes from using service robots in their working environment. Our findings allows for better understanding resistance and susceptibility of different users in a hospital and encourages managerial awareness of varying demands, needs, and surrounding conditions a service robot must contend with. We also discuss general insights into presenting the Q-methodology results and how an affordance-based view could inform the adoption, appropriation, and adaptation of emerging technologies.

Keywords: health information technology, IT affordance, materiality, mixed methods, niche evolution, Q-methodology, service robots 


\section{Introduction}

Across the world, the healthcare industry is facing considerable pressure to improve accessibility, efficiency and cost structures while striving to sustain (or even improve) the quality of health service delivery. Providing healthcare to a rapidly aging population while using fewer resources has become a key challenge of this century in industrialized countries (Joint Institute for Innovation Policy of the European Commission, 2012). Thus, policy-makers and citizens have high expectations that technological innovations might solve_ or at least minimize—aspects of this problem (Hedberg \& Morosi, 2015).

Robots hold a particular fascination as autonomous artificial objects and devices programmed to serve the needs of human beings (Oborn et al., 2011). The idea that robots can help to support and care for future generations has manifested in fiction and has also recently captured the headlines of mass media as more and more 'success stories' are revealed (The Economist, 2014; The Wall Street Journal, 2012). Unsurprisingly, robotics has become a multibillion-dollar industry in just a few years (Barrett et al., 2012). Although first implemented in areas that were remote or separate from humans, such as manufacturing and assembly lines, robots are now entering environments where they will share workspaces with humans (Thrun, 2004).

Under the label service robots, these types of devices are designed to "[...] operate semi- or fully autonomously to perform services useful to the well-being of humans [...]" (International Federation of Robotics, 2016), considerably expanding the digitization of work processes in hospitals and other health organizations (Yoo et al., 2010). Service robots are already being used in many health contexts. They are used to deliver medications, specimens, meals, and heavy loads (Ozkil et al., 2009; Wang et al., 2015); to clean and disinfect hospital facilities (Cepolina \& Muscolo, 2014); and to perform medical tasks such as assisting with surgical procedures (Sergeeva et al., 2015) or supporting care activities (Alves-Oliveira et al., 2015). Initial studies show how service robots increased the effectiveness of health workers or have even rendered some of their activities obsolete—such as patient registration or the packaging and dispensing of drugs, all of which can now be automated (Jayawardena et al., 2014; Ljungblad et al., 2012; Nejat et al., 2009). 
Almost $\$ 20$ billion is appropriated for facilitating the adoption and renewal of health technologies in the U.S. in the near future. In Western Europe, the modernization of the healthcare sector is expected to generate growth in spending from $\$ 13.2$ billion in 2013 to $\$ 14.6$ billion in 2018 (IDC, 2015). Although most of this will be spent on widening the adoption of and/or improving the interoperability of traditional systems (e.g. electronic medical records or electronic prescribing systems), a considerable amount will likely be spent on the introduction of tele-surgery, robotic nurses, or home-based robotic assistants, among others (Forbes, 2014).

Admittedly, existing discussions of the adoption of robotic applications in healthcare mirror high hopes and aspirations, and often reflect the opinions of policy-makers and technologists (Hagele, 2016). However, what do bealth workers think about using service robots? Do they share the same technoenthusiasm? What expectations and fears do they associate with service robots in their near-future work environment? Can the desired results be achieved?

Given that neglecting end-user concerns is possibly the single greatest cause of failure when introducing new technologies in organizations (Iivari et al., 2010), we focus our attention on the end-user perspective. Because service robots are still in an initiation/immature phase and 'topical ownership' in organizations is typically unclear, we focus on the views of opinion leaders (i.e. those who can influence others but are not seen as experts in the area of service robots) and opinion formers (i.e. those who are knowledgeable or have first-hand experience with service robots) in hospitals. A large body of knowledge clearly shows that individual beliefs and initial expectations significantly influence later usage behaviors and the infusion of technology (Al-Natour \& Benbasat, 2009; Nevo \& Wade, 2007; Sabherwal et al., 2006). At the same time, an increasing number of studies have shown that end-users develop quite different views about the action possibilities and opportunities of an IT artifact-in the literature, this is referred to as IT affordances (Leonardi, 2011; Seidel et al., 2013; Treem \& Leonardi, 2013).

To answer the above questions, we build on and extend the literature on IT affordances in two primary ways. First, based on the idea of ecological niches, we introduce a new concept as a means to cluster endusers with shared beliefs and perceptions about the affordances of service robots. As we will show, this knowledge can be instrumental in the adoption, appropriation, and adaptation of emerging technologies, 
such as robots, in practice. Second, we demonstrate how such niches can be identified by using a mixed research approach called Q-methodology. This method is specifically designed for studying the subjectivity of individuals (Stephenson, 1986) and is therefore different to typical survey-based research designs in that it seeks to capture a wide range of individual perspectives, opinions, and attitudes by using self-referencing statements and asking respondents themselves to sort statements according to specific sorting instructions (Brown, 1993).

The remainder of this paper is organized as follows. In Section 2, we provide an overview of the different uses and possible application areas of service robots in healthcare. In Section 3, we discuss this study's theoretical grounding. In Section 4, we explain our research method, data collection, and data and analysis. In Section 5, we present and discuss the empirical results. We conclude by highlighting our primary study contributions and their implications for research and practice in service robotics and IS research in general.

\section{Definition and Scope of Service Robotics in Healthcare}

Before we investigate how health workers perceive the affordances of service robots, we clarify the term and provide examples. Following Haidegger et al. (2013), a service robot is a machine that is able to perform tasks in an unconstrained, human-centered environment. Similarly, the International Standardization Organization (2016) defines a service robot as a machine "that performs useful tasks for humans or equipment, excluding industrial automation applications." Contrary to industrial robots, which often operate in controlled domains and/or domains that are hostile to humans (e.g. mining, assembly lines, outer space), service robots commonly function alongside humans and in a fairly uncontrolled environment.

Following Prestes et al. (2013), usage domain is also a good reference point for further categorization. In healthcare, we can distinguish between robots designed for the 'clinical world' (or for use in care facilities) and the 'non-clinical world' (or for use in patients' homes) (Mettler \& Raptis, 2012). Since we investigate health workers' concerns relating to the introduction of robots in their organizational settings, we limit our scope to devices designed for application in hospitals and professional care facilities. 


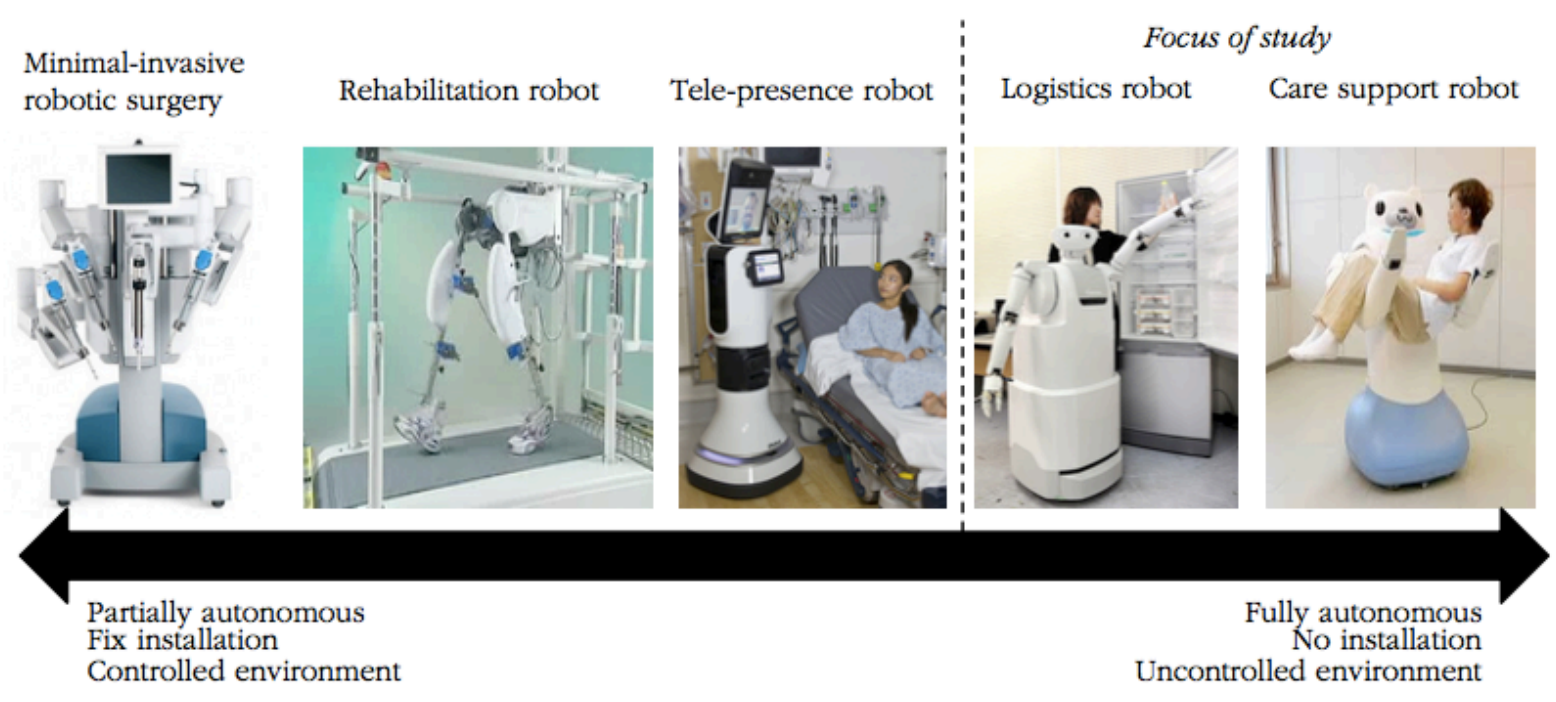

Figure 1. Examples of service robots for the hospital context.

As illustrated in Figure 1, there is a wide range of robots for different use cases and with different autonomy levels. The most prominent in hospitals today are stationary or tele-operated devices, such as robots that assist with surgery, rehabilitation, information, or drug-dispensing (Ahn et al., 2014; Barrett et al., 2012; Bepko Jr et al., 2009; Berlinger, 2006). Inherent to this robot type is that actions and tasks require some extent of human intervention or fixed installation to function properly; for instance, a surgeon handling a haptic input device to maneuver certain instruments of a surgery robot (Bodner et al., 2004), a physiotherapist assisting patients to perform pre-configured physical exercises (Riener et al., 2005), or a nurse using her computer to video-chat with patients and to remotely control the movement of a telepresence robot (Tsui et al., 2011). While there is evidence that these applications are helpful, most people would not associate robots with them (Diprose et al., 2012). We focus on service robots with higher autonomy than tele-operated remote devices and that do not require a controlled environment or fixed installation in hospitals to deliver intangible, automated, or personalized services to humans; for instance, a logistics robot that can navigate autonomously in uncontrolled environments (e.g. crowded hallways or areas with many obstacles) to deliver meal trays, sterile supplies, blood samples, mail, and so on (Deery, 1997; Kirschling et al., 2009), or a care support robot that enables immobilized patients to retrieve objects from boxes and shelves or can lift them from their bed (Nejat et al., 2009). 


\section{Affordances and Niches as Ways of Studying the End-User Views of Service Robots}

The theory of affordances was introduced by the ecologist Gibson (1979) to study the limits and possibilities a material offers an actor. In IS, this theory has been popularized for analyzing and researching the technology appropriation process and for explaining the interdependency of human agency and the materiality of technology without being either technologically or socially deterministic (Leonardi, 2011; Pozzi et al., 2014; Seidel et al., 2013; Volkoff \& Strong, 2013). For instance, Leonardi (2011) applies affordance theory to investigate the relatedness of the material and the social by analyzing how a technology's properties (or features) relate to individuals' subjective goals and perceptions. According to Leonardi (2013), materiality in this sense means “the arrangement of a technological artifact's physical and/or digital materials into particular forms that endure across differences in place and time and are important to users." Accordingly, materiality is intrinsic to technology, independent of its use and the context in which it is used, while affordances are understood relative to individuals' perceptions and my therefore be dependent on the person's experience, knowledge, culture, or ability to perceive (Davern et al., 2012; Treem \& Leonardi, 2013).

This relational notion of affordances has led IS scholars to develop different stances and interpretations (Lanamäki et al, 2016). One research stream has propagated a canonical view, assuming that primarily social conventions determine the meanings and existences of affordances (Barentsen \& Trettvik, 2002; Bertelsen, 2006). For example, the affordance of a keyboard is for typing. It is neither the end-user nor the designer who established this meaning; sociocultural and/or organizational influences shaped this understanding over time. In this sense, an IT artifact's purposes have existed prior to design and use and are therefore fairly stable, universal, and uncontroversial (Costall, 1997).

Contrary to the assumption of existing canonical affordances, a second research stream has developed that understand affordances as potentials for different actions and behaviors arising from the relationship between the artifact and a goal-oriented individual who seeks to achieve an immediate concrete outcome (Faraj \& Azad, 2012; Volkoff \& Strong, 2013). Building on a critical realist perspective, affordances are viewed as generative mechanisms that need end-users and designers to be uncovered, but which can exist regardless of a specific individual (Bygstad et al., 2016; Demir, 2015). This is possible because certain 
individuals share the same sociocultural identity or organizational context and can therefore decipher an artifact's potentials in a similar way (Majchrzak and Markus, 2012).

Rejecting the idea that affordances only need to be perceived by individuals in order to be real, a third research stream follows a pragmatist stance, as proliferated by Shotter (1983), who argued that "an affordance is only completely specified as the affordance it is when the activity it affords is complete." Thus, affordances are seen as the results of a creative co-construction between an IT artifact and a enduser (Oudshoorn \& Pinch, 2003); in other words, an affordance only comes into existence when it is actualized by an individual and expires when this action is completed (Lanamäki et al, 2016). This means that an affordance is temporally and spatially limited, since it is just valid for a situated context.

Finally, there is a fourth stance that understands affordances as a concept to describe the perceived properties of an artifact, primarily the fundamental properties that determine just how a technology could possibly be used (Norman, 1990). An affordance thus suggests the range of opportunities an artificial object—in our case a service robot—provides humans for extending, modifying, or substituting naturally embedded resources in their environment. The perceived properties attributed to an artifact, which may or may not actually exist, are the results of dynamic relationships or interactions among self-subsistent entities, namely the designer, end-user, and the artifact. In this sense, an affordance depends on both the current state of the environment, technology (i.e. materiality) as well as an individual's ability to interpret and perceive new opportunities for action. Besides the previous stances, this view also asserts that affordances can actively be designed into an IT artifact. However, similar to the first and second perspectives, it also relies on the perceptions of end-users who are predisposed by sociocultural or organizational influences.

For our analysis, we opted to apply the latter perspective since, in our view, canonical affordances of service robots are not yet present, and Norman's (1990) conceptualization of affordances is particularly useful for exploring emerging technologies where designers still have the possibility to shape our perceptions about robots. In applying this view, we acknowledge the fact that affordances are subject to change and that environmental cues affect the ways in which affordances are perceived by distinct users. Ecologists such as Gibson (1979) used the concept of niche to elucidate such shifts in perception and to 
explain how animals adapt differently to their environment. Following Gibson's understanding, a niche can be seen as a set of affordances for a particular animal. Different animals, with different abilities, may have physically collocated but nonetheless non-overlapping niches (Chamero, 2011). Studies have shown that animals seek to modify their surroundings through environmental selection to better exploit the features that best suit them and eliminate those that most harm them (Odling-Smee, 1988). Niche evolution has also been observed among humans as a strategy to better exploit the properties of artificial objects for problem-solving or decision-making (Magnani, 2008). Given the relational definition of affordances, and translated to this study's context, this means that an end-user's abilities to perceive and interact with service robots imply a niche. Conversely, a niche implies a group of end-users in which all members have similar perceptions of and similar uses for service robots. Accordingly, some niches may identify different affordances of service robots to others; some affordances may be shared by all end-users; some affordances that are common in other domains may remain unexploited.

To date, niches have seen insufficient attention in IS research. Mesgari and Okoli (2015) analyzed user adaptation patterns in open-source learning management systems by studying what they refer to as technoniches and user species. Hafermalz et al. (2015) suggest using niches to explore the interplays between social media and users' geo-locations. Both studies conclude that niches-understood as the relationships between user perceptions and artifacts—represent a useful way to make sense of technology. Against this backdrop, we employ the concept of niche to get a better understanding of health workers' contextual realities, since this has been identified as crucial to explaining adoption and resistance in healthcare (Kane et al., 2009). Our analysis highlights different patterns or clusters of shared beliefs concerning how service robots may or may not afford new practices, competencies, values, and norms. In turn, this is important for ascertaining whether materiality and/or the environment require further shifts in plans and practices so that service robots can be implemented successfully.

\section{Method}

To investigate what action possibilities health workers attribute to service robots and how these perceptions deviate between different niches, we use a mixed research approach called Q-methodology that 
has been widely used in various studies to uncover different thought patterns relating to the adoption and use of new technologies in different domains or settings (Baker et al., 2014; Best et al., 2010; Bouwman et al., 2012; Donner, 2004; Klaus et al., 2010; Rahim et al., 2011; Valenta \& Wigger, 1997). As noted above, Q-methodology seeks to systematically explore subjectivity by measuring a person's viewpoints, opinions, attitudes, and so on (Brown, 1993).

In contrast to current survey studies, which are designed to report sentiments as a composite average opinion, such as people's beliefs regarding what a robot should or should not do (Takayama et al., 2008), this research approach reveals combinations of varying opinions within a particular group of people and is therefore particularly suited to niche construction and the determination of perceived affordances related to service robots. Accordingly, although Q-methodology stands at the intersection of qualitative and quantitative research, it has a stronger emphasis on the qualitative lens of how and why (shared viewpoints or thought patterns) and a weaker emphasis on the quantitative prospect of how many (numerical distribution among a larger population). Thus, Q-methodology studies tend to use fairly small sample sizes (McKeown \& Thomas, 1988) and to yield phenomenologically rich results comparable to those of casebased research or other grounded theory methods (Klaus et al., 2010). However, since it includes a quantitative analysis, which is frequently missing in pure interpretative approaches, it also allows one to make some generalizations comparable to those obtained in empirical field research (Wingreen et al., 2009).

According to Brown (1993), a typical Q-methodology study includes four activities: collecting a wide range of perspectives on a topic, developing a set of statements commonly referred to as the Q-sample or Q-set that make a recognizable assertion about the topic, letting respondents compare and rank the Qsample statements concerning how much they agree or disagree with them (commonly known as Qsorting), and analyzing and interpreting the sorting exercise results by applying statistical factor analysis. We will now describe how we conducted these steps. 


\subsection{Concourse for Collecting a Wide Range of Perspectives}

Step 1 in our research process, called the concourse, involved an initial collection of statements, each making a different but nonetheless recognizable assertion about a particular topic. The goal was to obtain a comprehensive set of approximately 40 to 80 statements a person can make about the subject matter (Stainton Rogers, 1995). This is usually done through open-ended interviews or focus group discussions and backed up by evidence from printed sources such as journal publications, news articles, essays, or any other sources on the issue (Valenta \& Wigger, 1997). Notably, the concourse must not be theory-driven, as would be customary in survey studies; instead, it must reflect the opinion domain in a broad and representative way (Watts \& Stenner, 2012).

To obtain such a broad overview of possible perspectives, we conducted a scoping review on service robots (blind for review) and collected first-hand data via site visits, observations, and open-ended interviews with 15 hospital professionals (see Appendix). To recruit respondents for the interviews, we considered Thompson (1966), who noted that opinions are best assessed by people with a special interest or with particular expertise and authority regarding the subject matter. The interviewees were identified on the basis of referrals from robotics vendors and hospital managers and were contacted by phone or e-mail. In total, 15 health professionals with different professions and occupations in the hospital agreed to share their thoughts and experiences related to service robots (cf. Table 1).

Table 1. Participants involved in the concourse.

\begin{tabular}{|c|c|c|}
\hline Profession & $\begin{array}{l}\text { Interviewees } \\
\text { (duration of interview) }\end{array}$ & Main statements summarized \\
\hline \multirow[t]{2}{*}{$\begin{array}{l}\text { Administration/ } \\
\text { management }\end{array}$} & $\begin{array}{l}4 \text { x Head of organization } \\
\text { development }(1 \mathrm{~h})\end{array}$ & $\begin{array}{l}\text { Service robots bring forth a higher standardization of processes } \\
\text { and a higher level of control } \\
\text { O Service robots are an interesting topic, but not economically } \\
\text { beneficial } \\
\text { O Service robots could lead to resistance among nurses, clinicians, } \\
\text { and pharmacists }\end{array}$ \\
\hline & 4 x Hospital director $(1 \mathrm{~h})$ & $\begin{array}{l}\text { Building structure, high investment costs, and resistance of the } \\
\text { nursing personnel are perceived to be the main barriers to } \\
\text { service robots } \\
\text { O Service robots could lead to efficiency gains, which could free up } \\
\text { time that could be spent on more productive work } \\
\text { O Service robots are a good means of improving the hospital's } \\
\text { image, but an investment should be based on economic rationale } \\
\text { o Service robots might be useful but need a clear business case }\end{array}$ \\
\hline
\end{tabular}




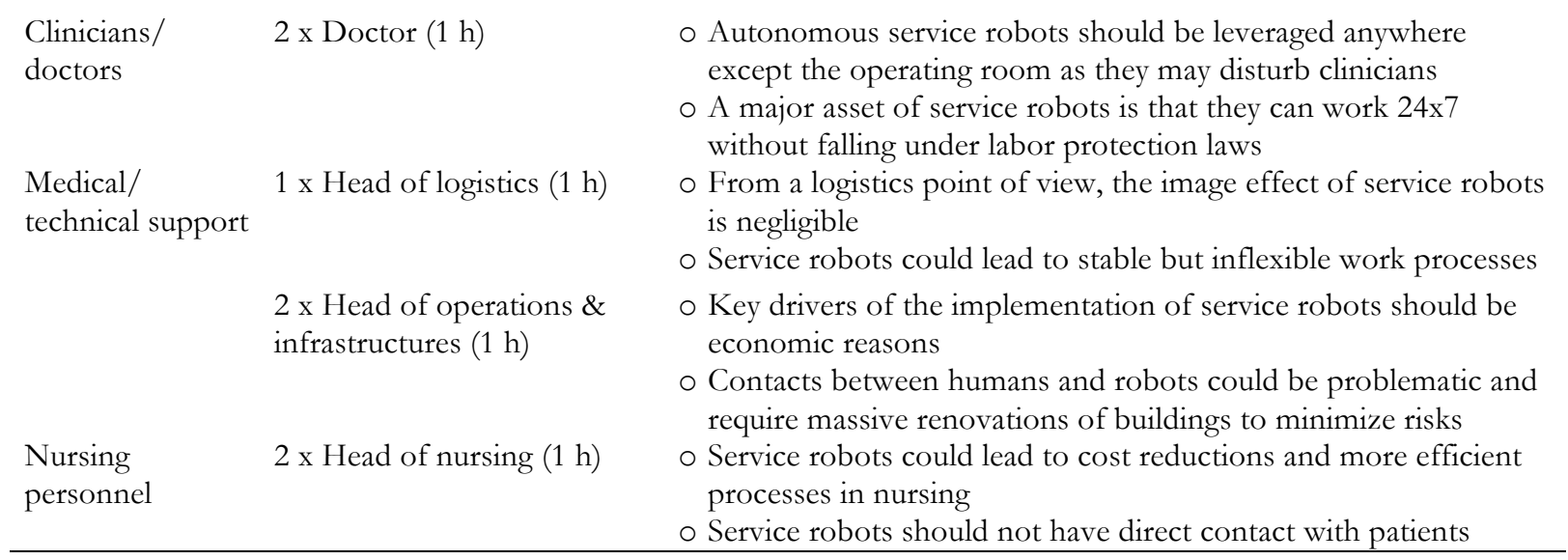

Each interview lasted approximately one hour and began with broad, unobtrusive questions about the current situation in the hospital and previous personal experiences with robots (at work and/or at home). This was followed by a clear definition of service robots and more specific questions about the future development of the hospital and service robots' possible roles in each interviewee's work area. During the interviews, we allowed an ongoing process of refocusing and reconceptualization, as suggested by Bouchard (1976), to allow the interviewees to reformulate their ideas more precisely with examples from their daily work experience. All interviews were recorded and the answers were transcribed verbatim; subsequently, these transcriptions were returned to the interviewees so that they could perform timely reviews for accuracy. Using an open-coding approach (Strauss \& Corbin, 1998), two researchers examined the interview transcripts line by line to ascertain the primary ideas, which were then verified and reformulated into cards (with each card containing a separate statement) by the interviewees themselves to capture their terminology. A set of 52 statements resulted from this first stage of the Q-methodology process.

\subsection{Developing the Q-sample}

In step 2, a subset of the concourse is selected to form what is referred to as the Q-sample or Q-set (Brown, 1993). This is mainly done to merge duplicates or very similar statements and to consolidate statements of opposite meaning. However, unlike survey studies that invest much effort into revising and simplifying the questionnaire to reduce the likelihood of of different interpretations, a Q-sample should retain the 
language used in the prior conversations, with the inherent ambiguity and looseness this implies (Baker et al., 2014). A Q-sample seeks to provide, 'in miniature', a comprehensive and representative set of statements drawn from the entirety of opinions accumulated in the concourse (Valenta \& Wigger, 1997). Prior research has shown that statements derived from a mix of the literature and interviews with domain experts are most likely to produce a representative sample (Dennis, 1988). However, the extant literature does not specify how the Q-sample selection procedure, often called the concourse process, should be performed. The literature generally separates the concourse process from the later Q-sorting procedure, which we will describe. However, we suspect that the selected number of statements also depends on the condition of instruction, which is used during the Q-sorting procedure to guide the study participants in arranging the statements along some specifications (e.g. rank-ordering or card distribution).

To obtain a manageable yet balanced set of cards with distinct perspectives about service robots for the subsequent sorting procedure (Donner, 2004), we reduced our initial set of 52 statements to 31 cards by merging similar and removing opposite statements. To facilitate the later interpretation of the results, we classified the cards into five categories: Drawing on Mirani and Lederer (1998), we categorized statements expressing either strategic, transactional, or informational impacts of using service robots. An additional category was defined to allocate all statements that conveyed emotional beliefs about service robots. The last category comprises all statements that referred to environmental or contextual cues. To not bias the study participants, this categorization was only used internally and was therefore not part of the ensuing Qsort procedure.

\subsection{Performing the Q-sort}

Step 3 of our research process, the Q-sort, can be regarded as the Q-methodology's core. In its simplest form—as in a card-sorting exercise - the study participants are asked to position, iterate, and re-arrange the Q-sample statements on a continuum (of most agreeable to the most disagreeable cards) until they are comfortable with the placement of the items relative to each other (Donner 2004). Instead of carrying out such a complete 1 to $\mathrm{n}$ rank ordering, and for reasons of simplicity and pragmatism, Q-methodology studies often apply a fixed quasi-normal distribution — a predefined allotment pattern for the card-sorting 
exercise, as shown in Figure 2-so that the finite possibility of configurations of cards is reduced (Baker et al., 2014; Valenta \& Wigger, 1997). This makes the rank-ordering of opinion statements easier for study participants (Watts \& Stenner, 2012). According to van Exel and De Graaf (2005), the chosen distribution's kurtosis (i.e. the steepness of the allotment pattern) should depend on how controversial the subject matter is: "П]n case the involvement, interest or knowledge of the respondents is expected to be low, $[\ldots]$, the distribution should be steeper in order to leave more room for ambiguity, indecisiveness or error in the middle of the distribution." Accordingly, "[...] in case respondents are expected to have strong, or well articulated opinions on the topic at issue, the distribution should be flatter in order to provide more room for strong (dis)agreement with statements."

Because we expected that the study participants had limited de facto experience with service robots, as most hospitals are still in the initiation and the adoption phases, we chose a fixed quasi-normal distribution with a 7 -point scale (with values ranging from $+3=$ most agreeable, to $0=$ indifference, to $-3=$ most disagreeable).

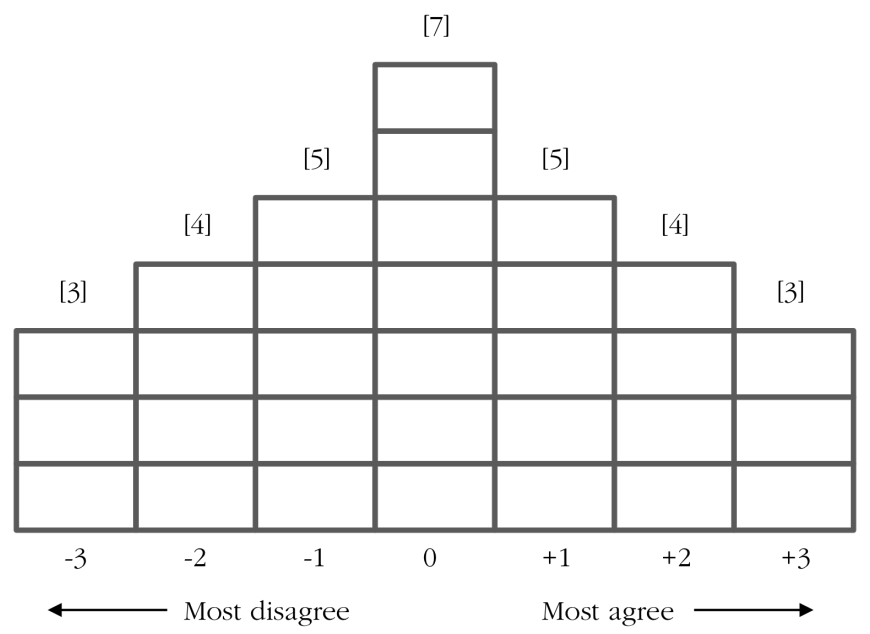

Figure 2. Fixed quasi-normal distribution used in this study.

To support the sorting procedure, we used a software called $Q$-sortware that allows researchers to create, collect, and administer all necessary data for Q-methodology studies online. Our Q-sort procedure followed a design similar to that suggested by O'Leary et al. (2013) and involved three activities: First, the 
Q-sortware tool presented study participants with one Q-sample statement at a time and allowed them to drag-and-drop each card into one of three piles: agree, disagree, or neutral. All cards were presented randomly. After the participants completed the initial sorting stage, they were given the option to review their piles and to make changes or to continue.

Second, the participants were asked to put the three statements with which they most agreed and most disagreed in the designated boxes in the table and then to sort the remaining statements to fit with the predefined quasi-normal distribution shown in Figure 2. Finally, the study participants had the opportunity to provide more detailed information (in a free-text field) on how and why they interpreted the cards they had ranked especially high or low in their Q-sort, and what implications these cards had in the context of their overall perspective. In an additional free-text field, they could also propose further statements and comment on cards that they had not understood or had found confusing. These comments were particularly useful for our later analysis and interpretation of findings.

The selection of our participants for the Q-sort exercise was driven by the classic methodological tradeoff involved in mixed research: while mere purposive sampling leads to greater depth of information obtained from a smaller number of carefully selected respondents, probability sampling leads to a greater breadth of information that may help to capture the opinions of a more representative population (Patton, 2002). Thus, we chose a multilevel stratified purposive sampling approach, also referred to as "samples within samples" (Patton, 2002), to select new study participants separate from the previously interviewed experts. The stratified nature of this sampling procedure is characteristic of probability sampling, while the small number of cases it generates is typical of purposive sampling. Using this technique, the researcher first divides the group into strata and then selects a small number of cases to study intensively within each stratum, based on purposive sampling techniques (Teddlie \& Yu, 2007). 

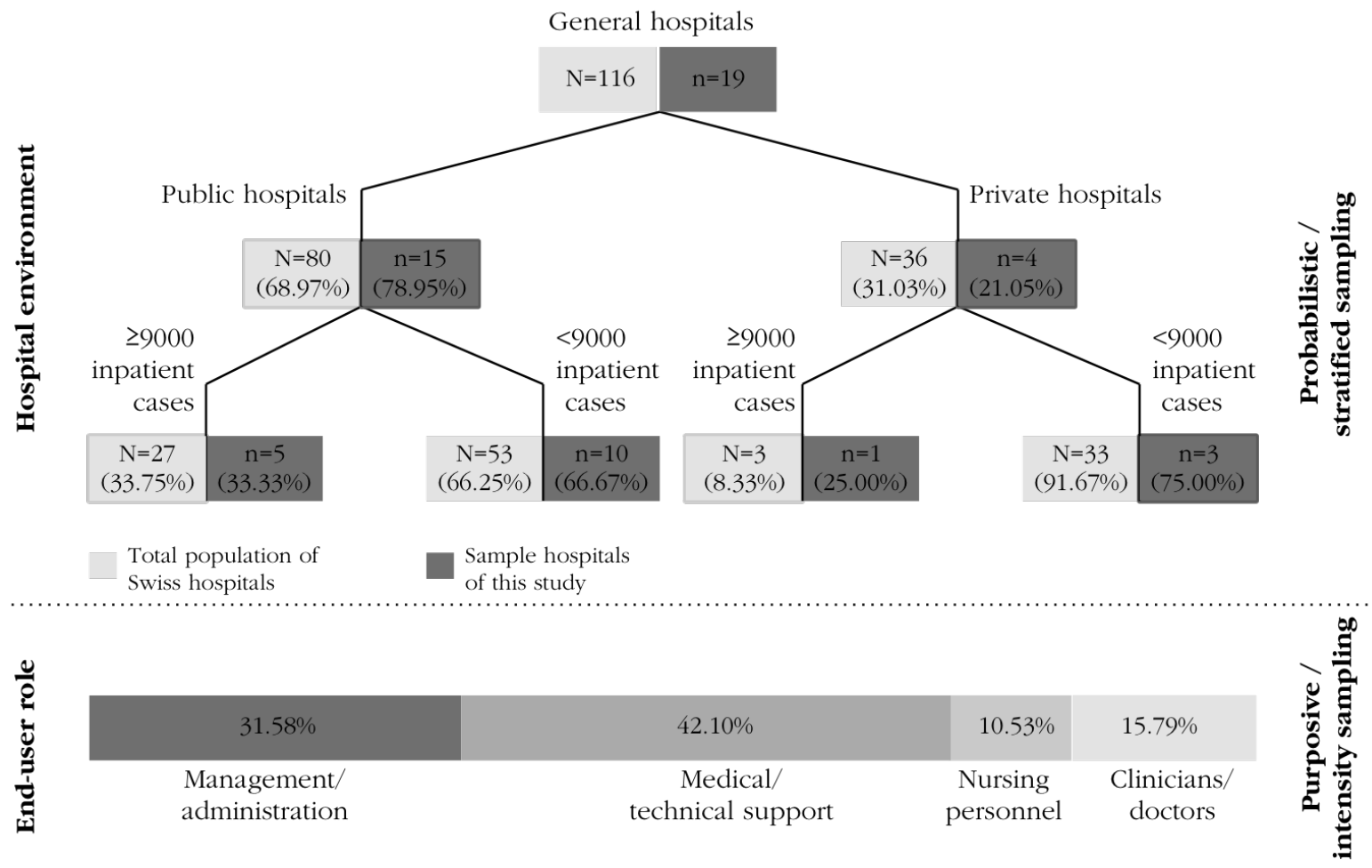

Figure 3. Multilevel sampling procedure used in this study.

As shown in Figure 3, we started with stratified sampling at the organizational level to split the population into representative subgroups (or strata), such that each hospital belongs to a single stratum. In Switzerland, where this study originated, hospitals are comprehensively portrayed in 6-monthly reports by the Swiss Federal Statistical Office (2016). As at 2014, Switzerland had 116 hospitals (80 public; 36 private). Using the number of impatient cases as a proxy for size (with 9,000 cases per year as the cutoff point), 30 hospitals ( 27 public, 3 private) were classified as large and 86 hospitals (53 public, 33 private) as small institutions. We tried to replicate the Swiss health system's structure by selectively including representatives from both publicly and privately owned small (10 public, 3 private) and large (5 public, 1 private) hospitals. However, we excluded specialized hospitals from our sample (e.g. psychiatric clinics, rehabilitation clinics, and nursing homes), since they operate under very different financial agreements and conditions than general hospitals.

At the individual level, we used intensity sampling to identify a small number of opinion formers and/or opinion leaders in the selected hospitals. Again, we relied on referrals from robotics vendors and 
hospital managers to identify potential respondents. A total of 19 health professionals agreed to take part in the Q-sort exercise. The respondents' demographics per identified niche appear in Table 2.

As with any qualitative inquiry, the number of study participants required to obtain a diversified big picture about service robots needed to be determined based on the principle of data saturation. Following Baker et al. (2014), this is reached when the Q-sort of an additional respondent will add little or no new information, i.e. his or her thought pattern can be described by the factors emanating from the previous Q-sorts of other respondents. To determine this data saturation point, we examined the progression of factor emergence as equivalent to the concept of cumulative audit trails used in the context of qualitative interviews (Guest et al., 2006). As illustrated in Figure 4, we assumed data saturation at approximately 13 Q-sorts, or after the emergence of five factors. We will now explain what these factors mean and how we calculated them. We included the Q-sorts of 19 study participants to ensure that the Swiss health system is well represented at an organizational level (i.e. representative distribution of public/private and small/big general hospitals).

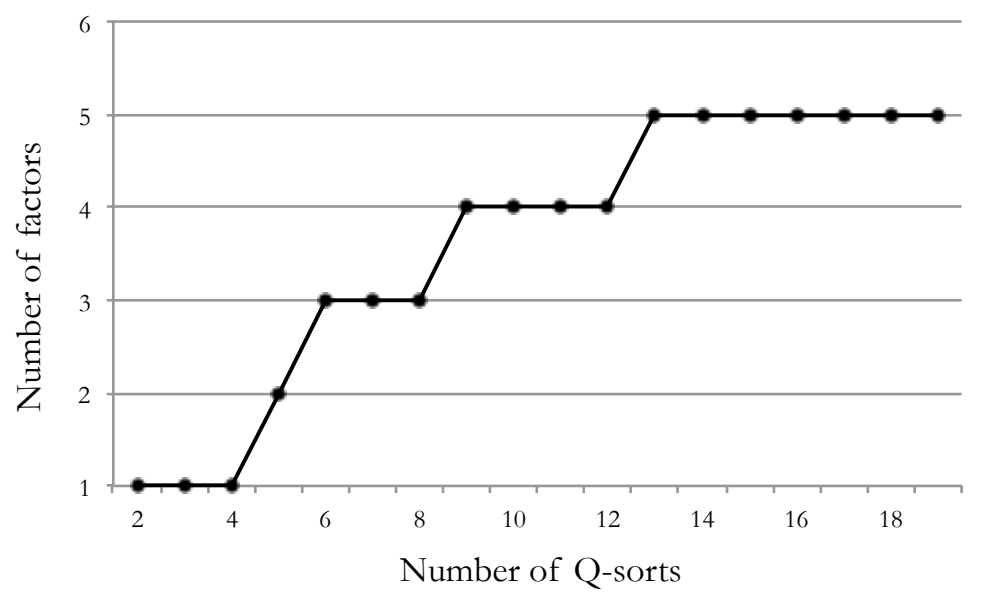

Figure 4. Progression of factor emergence calculated based on Q-sorts from 19 respondents.

\subsection{Quantitative Analysis Using Principal Component Analysis}

In Q-methodology, mixing occurs during data analysis in that the qualitative strand is quantitatively analyzed and data from both strands are merged, so that a comprehensive interpretation of the results is 
possible. The data obtained from a sorting exercise is transformed and assessed using a by-person correlation and factor analytical procedure (Watts \& Stenner, 2012). By applying the statistical method of factor analysis to the obtained set of Q-sorts, it is possible to identify, analyze, and interpret a small number of shared beliefs on an issue, as defined to varying degrees by the participants. However, unlike other applications of factor analysis, where participants are placed in rows and their responses to questions are placed in columns, an inverted matrix is used (with statements in rows and participants in columns). This is done to identify groups of similar participants with similar thought patterns (instead of identifying patterns inherent in the participants' answers). Thus, factor analysis is used to determine a set of factors onto which the study participants load on the basis of the item configurations (Q-sorts) they have created. It is assumed that study participants who load onto the same factor will have responded very similarly; in other words, each factor represents a niche.

However, Q-methodology makes no psychometric assumptions. All the responses are placed on a common scale reflecting their importance to the participant and their relationships to the other items (McKeown \& Thomas, 1988). Factor extraction follows the same rationale as in any other factor analytical study. Watts and Stenner (2012) recommend using principal component analysis (PCA) with Varimax rotation to pursue a rotated solution, which maximizes the amount of variance explained by the extracted factors. They propose only choosing factors with an eigenvalue $\geq 1.00$, while McKeown and Thomas (1988) suggest that, to also reflect theoretical and practical considerations for the determination of the total number of factors to be included in the study, a factor must ordinarily have at least two Q-sorts that load significantly on it alone (Watts \& Stenner, 2012). According to McKeown and Thomas (1988), significance at the $\mathrm{p}<0.01$ level is achieved when a factor loading is greater than 2.58 times the standard error for the loading, which is calculated as $1 / \sqrt{ } \mathrm{N}$, where $\mathrm{N}$ is the number of statements. Alternatively, Donner (2004) posits that participants are considered to define a factor when they load approximately 0.45 (or greater) on a single factor. We used the STATA software version 13.1 to perform the recommended PCA with Varimax rotation and to extract a total of five factors, which we will discuss and interpret in the following sections. 


\section{Results}

Based on the Q-methodology procedure and the guidelines described above, we identified five factors. Table 2 shows the factor loadings of the rotated factor matrix for each of the study participants concerning the five niches. The PCA yielded five factors, each of which represents a distinct niche of service robot end-users in hospitals $\left(\mathrm{N}_{1}=4\right.$ respondents; $\mathrm{N}_{2}=6$ respondents; $\mathrm{N}_{3}=4$ respondents; $\mathrm{N}_{4}=3$ respondents; $\mathrm{N}_{5}=2$ respondents). From Table 2, we also see that a respondent's profession and hospital size did not presuppose an affiliation with a niche. We also presumed that ownership did not influence belonging to a niche, because a definite pattern could not be found. Overall, the obtained solution accounts for $69 \%$ of the total variance, which is a fairly good approximation.

In the subsequent sections, we will analyze and interpret the identified niches based on the factor scorenot factor loadings, as typically used in factor analysis. A factor score can be understood as the (dis)agreement level (+3 to -3 ) attributed to each statement by a niche. It represents the score for a statement as a type of average of the scores given to that statement by all the Q-sorts associated with the factor (Brown, 1993). Before we go into niche evolution, we will first describe the most agreeable and disputable statements of the Q-sorts. 
Table 2. Participants involved in the Q-sort ordered by factor loadings.

\begin{tabular}{|c|c|c|c|c|c|c|c|c|}
\hline Ownership & $\mathrm{Size}^{\dagger}$ & Profession & Sex & $\mathbf{N}_{1}$ & $\mathbf{N}_{2}$ & $\mathbf{N}_{3}$ & $\mathbf{N}_{4}$ & $\mathbf{N}_{5}$ \\
\hline Public & $\mathrm{L}$ & Nursing personnel & $\mathrm{F}$ & ${ }^{x} 0.785^{*}$ & -0.223 & 0.108 & 0.260 & 0.007 \\
\hline Private & $\mathrm{L}$ & Clinicians/doctors & M & ${ }^{x} 0.778^{*}$ & 0.177 & -0.033 & -0.056 & 0.098 \\
\hline Public & S & Administration/management & $\mathrm{F}$ & ${ }^{x} 0.744^{*}$ & 0.113 & -0.059 & 0.273 & -0.232 \\
\hline Public & S & Medical/technical support & M & ${ }^{x} 0.655^{*}$ & 0.046 & 0.052 & 0.001 & 0.247 \\
\hline Public & S & Administration/management & M & 0.173 & ${ }^{x} 0.760^{*}$ & 0.019 & 0.116 & -0.077 \\
\hline Public & S & Medical/technical support & M & 0.084 & ${ }^{x} 0.676^{*}$ & -0.022 & -0.090 & 0.413 \\
\hline Public & S & Medical/technical support & M & 0.236 & ${ }^{x} 0.563^{*}$ & -0.232 & $0.515^{*}$ & 0.054 \\
\hline Public & $\mathrm{L}$ & Medical/technical support & M & $0.491^{*}$ & $x_{0.548^{*}}$ & 0.033 & 0.358 & -0.075 \\
\hline Private & S & Clinicians/doctors & M & 0.086 & ${ }^{x} 0.541^{*}$ & 0.199 & 0.060 & 0.446 \\
\hline Public & $\mathrm{S}$ & Medical/technical support & $\mathrm{M}$ & 0.062 & ${ }^{x_{0.469 *}}$ & $-0.755^{*}$ & 0.121 & 0.153 \\
\hline Private & $\mathrm{S}$ & Medical/technical support & $\mathrm{M}$ & -0.03 & -0.286 & ${ }^{x} 0.805^{*}$ & 0.237 & 0.059 \\
\hline Public & S & Administration/management & M & 0.023 & 0.181 & ${ }^{x} 0.794^{*}$ & -0.039 & -0.071 \\
\hline Private & S & Administration/management & M & $0.505^{*}$ & 0.211 & ${ }^{x} 0.608^{*}$ & -0.181 & 0.234 \\
\hline Public & S & Nursing personnel & $\mathrm{F}$ & 0.265 & $-0.664^{*}$ & ${ }^{x} 0.507^{*}$ & 0.050 & -0.089 \\
\hline Public & S & Medical/technical support & $\mathrm{M}$ & -0.118 & 0.266 & -0.301 & ${ }^{x} 0.736^{*}$ & 0.232 \\
\hline Public & $\mathrm{L}$ & Medical/technical support & M & 0.337 & 0.076 & 0.287 & ${ }^{x} 0.709^{*}$ & -0.231 \\
\hline Public & S & Administration/management & $\mathrm{M}$ & 0.319 & -0.450 & 0.203 & ${ }^{x} 0.594^{*}$ & -0.044 \\
\hline Public & S & Clinicians/doctors & $\mathrm{M}$ & -0.086 & 0.042 & -0.142 & 0.191 & ${ }^{x} 0.822^{*}$ \\
\hline Public & $\mathrm{L}$ & Administration/management & M & 0.285 & 0.131 & 0.049 & -0.267 & ${ }^{x} 0.741^{*}$ \\
\hline \multicolumn{4}{|l|}{ Eigenvalues: } & 4.298 & 3.672 & 2.260 & 1.544 & 1.353 \\
\hline \multicolumn{4}{|c|}{ Percentage of variance explained: } & $16.81 \%$ & $16.62 \%$ & $14.02 \%$ & $11.45 \%$ & $10.19 \%$ \\
\hline
\end{tabular}

† As described previously, we follow the guideline of the Swiss Federal Statistical Office and determine "hospital size" by means of the number of impatient cases, whereas $\geq 9000$ cases refer to a large hospital (L) and $<9000$ cases to a small hospital (S).

* Denote factor loadings that are significant, i.e. SE $=1 / \sqrt{ } \mathrm{N}$, where $\mathrm{SE}$ is the standard error and $\mathrm{N}$ is the number of Q-sort statements (Brown, 1993). For this study, the standard error comes out to $0.180(\mathrm{SE}=1 / \sqrt{31})=1 / 5.568=0.180)$. Correlations are considered to be statistically significant at the 0.01 level when they are in excess of 2.58 standard errors (irrespective of sign) or $2.58(0.180)=0.464)$.

$x$ Denote cases that are used to calculate niches. In order not to confound subsequent interpretation, we only assigned a person to a niche when he/she is positively correlated to a factor. In case of negative correlation, we chose the highest positive correlation for making the interpretation of results easier.

\subsection{Consensus and Disagreement among Niches}

To develop coherent narratives for the identified factors, it is advisable to first inspect the most and least shared beliefs among the niches. Table 3 illustrates the non-discriminative statements, which are the eight statements with the least standard deviations among the niches. They represent a certain consensus regarding service robot usage in the hospital environment.

All end-user groups generally share a key concern that the implementation of service robots will lead to stronger dependency on technology providers. Today, in the event of software problems, certain tasks can still be circumvented and executed manually, in one form or another. However, there is a strong fear that 
the continuity of fully automatized services could be jeopardized in the long run because people will lack the necessary knowledge to perform such workarounds. Interestingly, most participants considered people to be more reliable than robots. Further, hospital professionals do not think that the implementation of service robots would have a major impact on the hospital's strategy and would increase the flexibility of operations.

Table 3. Statements and factor scores of consensus items.

\begin{tabular}{|c|c|c|c|c|c|c|c|}
\hline No. & Description & $\mathbf{N}_{1}$ & $\mathbf{N}_{2}$ & $\mathbf{N}_{3}$ & $\mathbf{N}_{4}$ & $\mathbf{N}_{5}$ & SD \\
\hline 5 & $\begin{array}{l}\text { Service robots will cause new forms of privacy issues and therefore minimize } \\
\text { trust among our employees. }\end{array}$ & 0 & 0 & 1 & -1 & -2 & 1.14 \\
\hline 12 & Service robots will increase fixed costs for operating selective work processes. & 0 & 0 & 1 & -1 & 2 & 1.14 \\
\hline 14 & $\begin{array}{l}\text { The implementation of service robots is problematic because of the low } \\
\text { frequency of repetitive tasks. }\end{array}$ & -1 & 0 & 0 & 1 & 2 & 1.14 \\
\hline 20 & Service robots will provide us with new flexibility in our hospital strategy. & 0 & 0 & -2 & -1 & -1 & 0.84 \\
\hline 21 & In my opinion, service robots are more reliable than employees. & -1 & -2 & 0 & -2 & -3 & 1.14 \\
\hline 23 & $\begin{array}{l}\text { Service robots will provide us with more reliable information regarding selective } \\
\text { work processes in our hospital. }\end{array}$ & -2 & -1 & 0 & 0 & 1 & 1.14 \\
\hline 24 & $\begin{array}{l}\text { The implementation of service robots will have a major impact on our hospital } \\
\text { strategy. }\end{array}$ & -1 & -1 & -2 & 0 & -2 & 0.84 \\
\hline 26 & Service robots will increase our dependency on a technology provider. & 2 & 3 & 3 & 2 & 1 & 0.84 \\
\hline
\end{tabular}

Considerable disagreement exists on the statements in Table 4, which represent the eight statements with the largest standard deviations and are therefore valuable concerning distinguishing certain niches. For instance, the participants expressed opposite views on the supposition that service robots would improve a hospital's quality, costs, and image. They also disagree on the roles robots could play in reducing the workloads of low-skilled and high-skilled personnel. It also seems that the identified niches rated potential problems emerging from existing building structures (e.g. the existence of ground sills, narrow elevators and rooms) and IT architectures (e.g. proprietary hospital information systems, missing application programming interfaces) very differently. 
Table 4. Statements and factor scores of distinguishing items.

\begin{tabular}{rlcccccc}
\hline No. & Description & $\mathbf{N}_{1}$ & $\mathbf{N}_{2}$ & $\mathbf{N}_{3}$ & $\mathbf{N}_{4}$ & $\mathbf{N}_{5}$ & $\mathbf{S D}$ \\
\hline 1 & The basic structure of our hospital buildings affects the usage of service robots. & 3 & 2 & -2 & 3 & -1 & 2.35 \\
3 & Service robots will cause new types of integration problems with our IT. & 3 & 0 & -2 & 3 & 3 & 2.30 \\
4 & Areas with many human encounters are problematic for the implementation of \\
service robots in our hospital today. & 1 & 2 & -3 & 0 & -2 & 2.07 \\
6 & Service robots will reduce the operating costs of the entire hospital. & 1 & -3 & 0 & -3 & 2 & 2.30 \\
8 & Service robots will improve our image as an innovator in the healthcare industry. & -2 & -3 & 1 & 1 & -3 & 2.05 \\
10 & Service robots will improve the quality of our services. & -1 & 2 & -3 & -1 & 3 & 2.45 \\
11 & Service robots will reduce the workloads of low-skilled jobs. & 3 & -1 & -3 & -2 & -2 & 2.35 \\
17 & Service robots will reduce the workloads of high-skilled jobs. & 1 & -2 & 3 & 0 & -1 & 1.92 \\
\hline
\end{tabular}

\subsection{Service Robots as Means of Reducing the Workloads of Hospital Professionals $\left(\mathbf{N}_{1}\right)$}

The first niche represents end-users who shared a strong belief that robots could support hospital professionals in reducing their workload and, in doing so, could reduce the variable costs of operations in the organization. This sentiment is particularly strong for tasks performed by lower-skilled employees. However, respondents did not presume that robots would solve existing or upcoming workforce problems, particularly in the nursing field.

This niche's members have strong concerns relating to the complexity of this new technology and the potential issues it might create when integrated into the physical structures of buildings and the organization's metaphysical IT architecture. They also had reservations concerning the flexibility of the use of service robots and assumed that robots are deployable for selective work processes only and will be of little value in generating new information that has not previously been available. Thus, members of this niche are aware of the fact that their environment (e.g. building plans, extant IT systems) could limit the perceived affordances of service robots. Table 5 shows the statements on which the members of this niche agreed/disagreed most. 
Table 5. Best and least supported statements describing $\mathrm{N}_{1}$.

\begin{tabular}{|c|c|c|c|c|c|c|}
\hline No. & Description & $\mathbf{N}_{1}$ & $\mathbf{N}_{2}$ & $\mathbf{N}_{3}$ & $\mathbf{N}_{4}$ & $\mathbf{N}_{5}$ \\
\hline$\circ 1$ & The basic structure of our hospital buildings affects the usage of service robots. & 3 & 2 & -2 & 3 & -1 \\
\hline$\circ 3$ & Service robots will cause new types of integration problems with our IT. & 3 & 0 & -2 & 3 & 3 \\
\hline$\circ 11$ & Service robots will reduce the workloads of low-skilled jobs. & 3 & -1 & -3 & -2 & -2 \\
\hline 15 & $\begin{array}{l}\text { Service robots will provide us with completely new information regarding selective } \\
\text { work processes in our hospital. }\end{array}$ & -3 & 1 & -1 & 1 & 0 \\
\hline 18 & Service robots will support us in solving our workforce problems. & -3 & -1 & 1 & 1 & 0 \\
\hline 28 & $\begin{array}{l}\text { Knowledge and experience with regulations influences the implementation of a } \\
\text { service robot in our hospital. }\end{array}$ & -3 & 0 & 0 & -1 & 2 \\
\hline
\end{tabular}

$\mathrm{x}$ Denotes consensus statements and ${ }^{\circ}$ denotes distinguishing statements.

\subsection{Service Robots as Strategic Assets for Tackling Spending Problems $\left(\mathrm{N}_{2}\right)$}

As seen in Table 6, the second group of hospital professionals is mostly driven by environmental and strategic concerns and disagrees with many of the emotional and transactional statements. Although the members of this niche share the view that service robots could help to improve spending allocations in their organization, they do not believe that the implementation of robots will lead to a decisive reduction in operating costs throughout the hospital. They are extremely skeptical that their hospital environment (e.g. owing to unsuitable floor plans or decentralized structures) will allow the robots to exercise their full potential. Accordingly, they assume that robots will have little impact on the hospital's image.

Similar to the previous niche, members of this niche believe that service robots will enable cost reductions in selected process areas only. However, unlike members of niche 1, they expect some positive effects relating to information generation and service quality. The members of niche 2 are aware that this might possibly come with the risk of security threats and a stronger dependency on technology providers, since they might lack the expertise to install and maintain service robots by themselves. They also anticipate that the implementation of service robots will face resistance in their hospital, such that they prefer to wait and see whether other hospitals report positive business results from this technology rather than being a pioneer in healthcare by introducing robots. Thus, service robots represent a new strategic option for this niche; members might consider it worthwhile for the hospital's clearly defined problem areas. 
Table 6. Best and least supported statements describing $\mathrm{N}_{2}$.

\begin{tabular}{rlccccc}
\hline No. & Description & $\mathbf{N}_{1}$ & $\mathbf{N}_{2}$ & $\mathbf{N}_{3}$ & $\mathbf{N}_{4}$ & $\mathbf{N}_{\mathbf{5}}$ \\
\hline 19 & Service robots will support us in solving our spending problems. & 2 & $\mathbf{3}$ & 2 & 2 & -1 \\
x26 & Service robots will increase our dependency on a technology provider. & 2 & $\mathbf{3}$ & 3 & 2 & 1 \\
30 & I think we will only implement service robots if other hospitals report positive & 0 & $\mathbf{3}$ & 0 & -2 & 1 \\
& experiences. & & & & & \\
$\circ 6$ & Service robots will reduce the operating costs of the entire hospital. & 1 & $\mathbf{- 3}$ & 0 & -3 & 2 \\
9 & I feel that the implementation of service robots will divide opinions in our hospital. & -1 & $\mathbf{- 3}$ & -1 & 0 & -3 \\
$\circ 8$ & Service robots will improve our image as an innovator in the healthcare industry. & -2 & $\mathbf{- 3}$ & 1 & 1 & -3 \\
\hline
\end{tabular}

x Denotes consensus statements and ${ }^{\circ}$ denotes distinguishing statements.

\subsection{Service Robots as Specialist Tools for Supporting Highly Skilled Hospital Professionals $\left(\mathbf{N}_{3}\right)$}

The members of niche 3 seem to be less circumspect towards robots than end-user niche 2. Although aware of a potential dependency on technology providers, they are very much in favor of implementing service robots in their hospital. They are positive that, if cost pressures and financial constraints continue, the introduction of service robots will be unavoidable in future.

This niche shares the perception of service robots as multitalented, specialist tools for expert professionals, capable of resolving some of the long-term workforce problems in their hospital. As seen in Table 7, they do not expect that this technology's introduction will improve the quality of delivered services, nor do they expect a major impact on the tasks of low-skilled employees. However, they do believe that previous knowledge and experience with robotic technology (e.g. stationary surgery or drugdispensing robots) will help ensure that it is fruitful to implement service robots. Members of this niche generally share the opinion that service robots will raise the organization' image and will positively impact on hospital spending.

Table 7. Best and least supported statements describing niche $\mathrm{N}_{3}$.

\begin{tabular}{|c|c|c|c|c|c|c|}
\hline No. & Description & $\mathbf{N}_{1}$ & $\mathbf{N}_{2}$ & $\mathbf{N}_{3}$ & $\mathbf{N}_{4}$ & $\mathbf{N}_{5}$ \\
\hline $\mathrm{x} 26$ & Service robots will increase our dependency on a technology provider. & 2 & 3 & 3 & 2 & 1 \\
\hline 27 & I am very much in favor of implementing service robots in hospitals. & 2 & 1 & 3 & 3 & 0 \\
\hline o17 & Service robots will reduce the workloads of high-skilled jobs. & 1 & -2 & 3 & 0 & -1 \\
\hline $\mathrm{o} 4$ & $\begin{array}{l}\text { Areas with many human encounters are problematic for the implementation of } \\
\text { service robots in our hospital today. }\end{array}$ & 1 & 2 & -3 & 0 & -2 \\
\hline$\circ 10$ & Service robots will improve the quality of our services. & -1 & 2 & -3 & -1 & 3 \\
\hline o11 & Service robots will reduce the workloads of low-skilled jobs. & 3 & -1 & -3 & -2 & -2 \\
\hline
\end{tabular}

x Denotes consensus statements and ${ }^{\circ}$ denotes distinguishing statements. 


\subsection{Service Robots as Gadgets with Unknown Practical Value $\left(\mathrm{N}_{4}\right)$}

Niche 4 reflects a very interesting yet controversial shared thought pattern about service robots. While members were positively disposed towards robots, they also expressed serious concerns relating to the physical limitations of buildings, restricted usage flexibility, and low frequency of repetitive tasks in work processes, all of which could prevent robots from functioning efficiently in hospitals. Although they shared some positive feelings towards robots, they are unclear about what robots will enable them to do better or differently in practice. Our analysis of the free-text answers led us to conclude that the members of niche 4 do not perceive service robots as serious work tools; they see robots as gadgets with as-yet-unknown utilitarian values.

The Q-sort revealed that, in niche 4, there is a particularly strong emphasis on the constraints and a weak focus on the affordances of service robots, making it hard to interpret the reasons why they expressed positive feelings about the introduction of service robots. Table 8 shows the statements the members of this niche agree/disagree with most.

Table 8. Best and least supported statements describing $\mathrm{N}_{4}$.

\begin{tabular}{rlccccc}
\hline No. & Description & $\mathbf{N}_{1}$ & $\mathbf{N}_{2}$ & $\mathbf{N}_{3}$ & $\mathbf{N}_{4}$ & $\mathbf{N}_{5}$ \\
\hline 27 & I am very much in favor of implementing service robots in hospitals. & 2 & 3 & $\mathbf{3}$ & 0 \\
o1 & The basic structure of our hospital buildings affects the usage of service robots. & 3 & 2 & -2 & $\mathbf{3}$ & -1 \\
○3 & Service robots will cause new types of integration problems with our IT. & 3 & 0 & -2 & $\mathbf{3}$ & 3 \\
22 & I think we will only implement service robots if cost pressures continue. & 0 & -1 & 1 & $\mathbf{- 3}$ & -1 \\
o6 & Service robots will reduce the operating costs of the entire hospital. & 1 & -3 & 0 & $\mathbf{- 3}$ & 2 \\
2 & I feel that the implementation of service robots will create resistance in our hospital. & -2 & 1 & -1 & $\mathbf{- 3}$ & 1 \\
\hline
\end{tabular}

x Denotes consensus statements and o denotes distinguishing statements.

\subsection{Service Robots as a Means of Boosting the Quality of Services and Information $\left(\mathbf{N}_{5}\right)$}

Finally, according to the members of niche 5 , service robots will afford an improved quality of services and will generate more reliable information regarding selective work processes than the technologies currently used in the hospital. This is somewhat contradictory, because they do not consider robots to be more reliable than people. A possible explanation could be that members of niche 5 expect problems with the integration of robots into the existing IT architecture, making them less effective and causing possible problems of reliability. 
Overall, members of niche 5 perceive the implementation of service robots as less problematic, although they are aware of the limitations on usage and of the increased fixed costs. As seen in Table 9, they do not believe that the introduction of service robots will create a major divide among hospital professionals. They also share the view that, at present, service robots will draw less public attention than what the other niches expect.

Table 9. Best and least supported statements describing $\mathrm{N}_{5}$.

\begin{tabular}{|c|c|c|c|c|c|c|}
\hline No. & Description & $\overline{\mathbf{N}_{1}}$ & $\mathbf{N}_{2}$ & $\mathbf{N}_{3}$ & $\mathbf{N}_{4}$ & $\mathbf{N}_{5}$ \\
\hline o3 & Service robots will cause new types of integration problems with our IT. & 3 & 0 & -2 & 3 & 3 \\
\hline 13 & Service robots will reduce the variable costs of operating selective work processes. & 1 & 1 & 0 & 0 & 3 \\
\hline$\circ 10$ & Service robots will improve the quality of our services. & -1 & 2 & -3 & -1 & 3 \\
\hline o8 & Service robots will improve our image as an innovator in the healthcare industry. & -2 & -3 & 1 & 1 & -3 \\
\hline 9 & I feel that the implementation of service robots will divide opinions in our hospital. & -1 & -3 & -1 & 0 & -3 \\
\hline $\mathrm{x} 21$ & In my opinion, service robots are more reliable than employees. & -1 & -2 & 0 & -2 & -3 \\
\hline
\end{tabular}

x Denotes consensus statements and ${ }^{\circ}$ denotes distinguishing statements.

\section{Research contributions and implications}

To date, most studies on the adoption of robotic applications and devices in healthcare have reported on opinions and experiences of policy-makers and technologists (Hagele, 2016). Although having a better understanding of end-user concerns has been proven to be vital for properly guiding the introduction of emerging technologies (Iivari et al., 2012), there has been a methodological and empirical gap to investigate the potentials of service robots for hospitals and care facilities. By using Q-methodology, our study was able to gain insights into the expectations and worries that health workers associate with service robots in their work environments. This led us to important theoretical and practical implications.

\subsection{Implications for Research}

This paper contributes to theoretical discussions concerning the use of an affordance theory for studying the adoption, appropriation, and adaptation of novel technologies (e.g. Leonardi, 2011; Seidel et al., 2013; Volkoff \& Strong, 2013). Following Norman's (1990) position that an affordance represents a range of opportunities, which can actively be designed into an IT artifact and which depend on end-users' abilities 
to interpret and perceive these opportunities for action, our study illustrates that the materiality of a technological artifact is inextricably linked with the subjective goals and perceptions of end-users (Faraj \& Azad, 2012). We further illustrate how the organizational context enables or restricts end-users from seizing the opportunities associated with an IT artifact.

To acknowledge the fact that affordances are subjective and are affected by environmental influences, we introduced the concept of niche, as proposed by Gibson (1979), to study the relationships between service robots, end-users, and their working environments. We identified five niches of end-users who attributed different affordances to the usage of service robots in hospitals: (1) a niche of end-users with a particular emphasis on transactional benefits and a strong belief that robots could help hospital professionals to reduce workloads and the variable costs of operations; (2) a niche that also associates robots with massive cost reduction potential throughout the hospital, but thinks that their current hospital environment will not allow robots to realize this potential; (3) a niche of extremely positive end-users who, above all, predict a bright future for service robots as assistive tools in expert domains; (4) a niche that is unclear about what robots will enable them to do; and (5) a niche of end-users that recognizes the informational benefits of using service robots because they generate more reliable information throughout the execution of work processes and thus help increase service quality in the hospital.

Our findings show that a niche of end-users does not necessarily evolve from a shared set of demographic characteristics. Our results provide evidence that a user's sociocultural background and working environment critically determines what he or she sees that a service robot will offer. This is fundamentally different from existing user profiling or clustering approaches (Li et al., 2012; Poulston et al., 2016), which often neglect users' perceptions and only consider demographic, usage, or location-based information (Kuo et al., 2009). In our view, such approaches are less helpful for studying the adoption of and resistance to emerging technologies, since they often suppress the fact that environmental influences, such as organizational policies or working conditions, affect the ways in which end-users adapt to and interact with technologies.

Methodologically, our study is innovative in that we apply a research method that is relatively unknown to IS research. Using Q-methodology, we showed how to capture shared beliefs of end-users, so as to 
describe which affordances are characteristic of which niche. We found Q-methodology to be a particularly suitable instrument for studying niche evolution, since it helps to uncover thought patterns beyond the composite average opinions of study participants and allows for in-depth analyses of shared beliefs and perspectives in a specific technology and use domain. This, in particular, differentiates our paper from existing Q-methodology studies in IS/IT (e.g. Bouwan et al., 2012; Valenta \& Wigger, 1997), which typically place less emphasis on the reciprocal relationship between end-users and their environment and how this relationship impacts the perceived affordances of a technology.

\subsection{Implications for Healthcare Organizations}

In focusing on end-users' emotional and contextual viewpoints regarding the use of service robots, rather than on socioeconomic or demographic segmentation, we identified different niches with varying demands, needs, and surrounding conditions that could serve as a basis for analyzing whether the extended, integrative, and emergent use of a technology is embraced or rejected by particular groups of health workers. This stage of IT infusion, as identified by Cooper and Zmud (1990), is only achieved when end-users can overcome their initial resistance to changing their inherent behaviors and are motivated to adopt new behaviors (Kim \& Kankanhalli, 2009). Several studies have reported on the strong opposition of health workers to adopting supporting technologies such as electronic medical records or (as in our case) service robots, which provide them with only indirect or delayed benefits (Bhattacherjee \& Hikmet, 2007; Doolin, 2004).

In many cases, sociodeterministic explanations of IT-enabled change overlook the IT artifact-the specific material and cultural properties in the form of hardware and/or software (Orlikowski \& Iacono, 2001) — and its roles in shaping how end-users actually perceive and use technologies. Applying Qmethodology along the implementation process as an alternative instrument for user and technology profiling could yield rich, detailed information about the ways end-users interpret a technology and how these perceptions possibly influence and moderate the evolutionary adoption, appropriation, and adaptation of innovation efforts in healthcare organizations (Goh et al., 2011). 


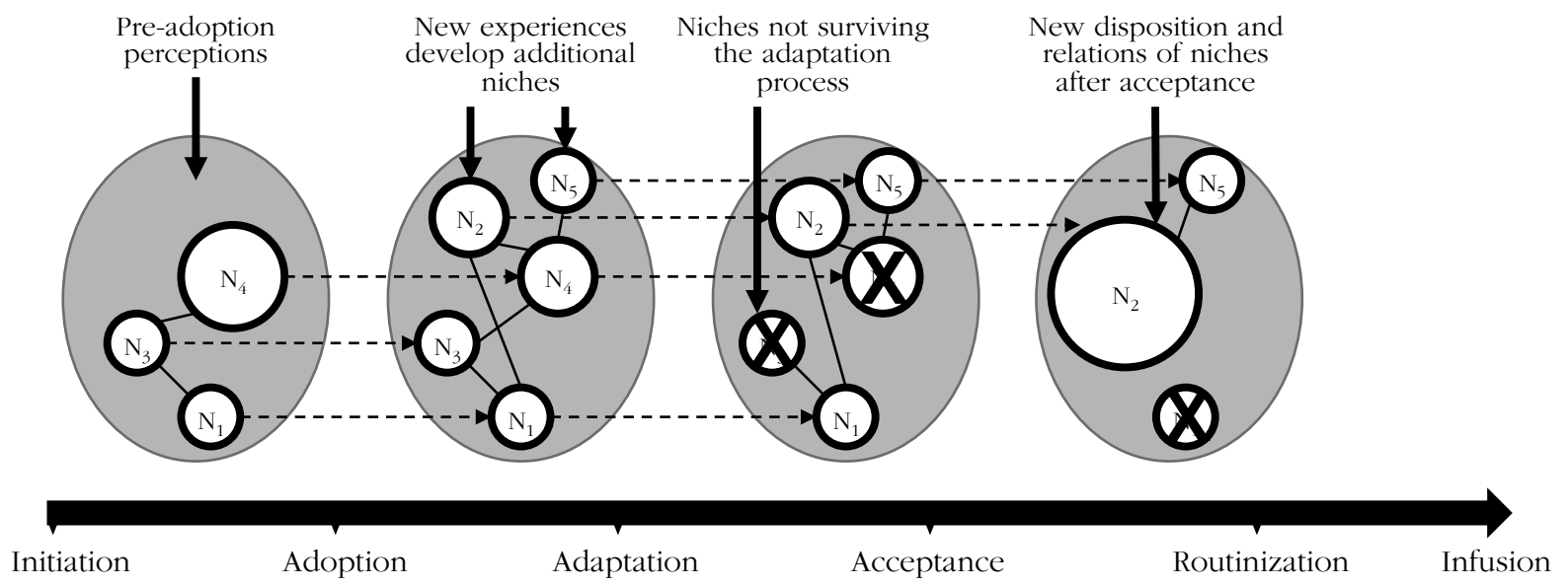

Figure 5. Using niche evolution to better understand the implementation process.

Figure 5 contains an illustration of a hypothetical scenario of an implementation process. Let us assume that an initial pre-adoption assessment reveals three end-user niches in a hospital. The biggest end-user niche $\left(\mathrm{N}_{4}\right)$ has no clear understanding of the possible impacts of service robots and thus sees them as a rather futuristic gimmick or as experimental gadgets that might help to support not-yet-concretely defined future goals or strategies. The other two minor factions in the hospital perceive service robots either as highly specialized tools $\left(\mathrm{N}_{3}\right)$ or contrariwise as fairly universal appliances for reducing the workload of low skilled health workers $\left(\mathrm{N}_{1}\right)$. To reduce negative perceptions of service robots, the hospital management decides to adopt both a highly sophisticated care support robot and a fairly easy-to-use logistics robot.

After the adoption of these dissimilar types of service robots, a second inquiry uncovers two additional niches. First-hand practical experiences and enhanced knowledge from using the robots have changed the thought patterns of certain end-users. Instead of seeing the robots as experimental gadgets, some health workers now understand the strategic value of robotic innovations $\left(\mathrm{N}_{2}\right)$ and thus conceive of new ways to improve the quality of health service delivery $\left(\mathrm{N}_{5}\right)$.

More extensive use of technology involves far-reaching adjustments to work processes and the organizational, socioeconomic, and/or cultural environments. An additional assessment after the initial adoption and adaptation phase reveals further shifts in the affiliations of distinct end-users or even leads to resolution in some niches, changing their views of service robots as toys $\left(\mathrm{N}_{4}\right)$ or as specialized tools $\left(\mathrm{N}_{3}\right)$. 
Finally, end-users change their routines if they perceive service robots as affording the achievement of their goals. In turn, this provokes additional alterations in the dispositions and relationships of existing niches, possibly leading to a dominant thought pattern, such as perceiving robots as strategic assets $\left(\mathrm{N}_{2}\right)$, and a less dominant view of seeing robots as a primary means to increase the quality of health services $\left(\mathrm{N}_{5}\right)$.

While Figure 5 portrays a fictional example of a service robot's implementation process in a hospital, it underlines the importance of niches as sense-making mechanisms through which health workers may frame their perceptions of affordances and decision-makers may determine the appropriateness of their measures in order to successfully implement a novel technology. It also shows that a better understanding of the existence and evolution of perceived IT affordances and corresponding niches may help to produce the intended organizational outcome, for instance, by counteracting or reinforcing the dominant or less dominant view of an IT artifact by influencing the environment or modifying the IT artifact. Our study corroborates the findings of previous research by acknowledging the key role of shared beliefs in change efforts (Battilana et al., 2009; Creed et al., 2010). However, we extend the prevailing discourse by introducing niches to conceptualize shared thought patterns and determining a possible working surface for governing and controlling the implementation process of a technology.

\subsection{Limitations}

IS researchers should be aware of the limitations of Q-methodology. While it allows one to generate new insights at a level of phenomenological richness comparable to case-based research or other grounded theory methods (Klaus et al., 2010), the typically small samples do not provide the basis for performing additional statistical tests to assess the relationships between niche affiliation and other demographic and occupational variables, such as profession, education level, gender, and age. In this sense, although we consider our insights to be valuable and generative, we cannot consciously transfer our findings to other industries or organizational contexts. While this paper could stimulate interest among IS scholars to consider Q-methodology in their research, we therefore accentuate the fact that findings are hard to generalize, since the data obtained from applying such a research method are not representative or objective in a positivist sense (McKeown \& Thomas, 1988). However, this opens new avenues for 
researchers to deliberate on ways how to improve internal validity, reliability, or external replicability of Qmethodology studies and how to present findings more convincingly.

\subsection{Conclusion and future research opportunities}

There has been a growing interest in IS research to develop frameworks, extant theories, and new stances to the concept of affordance (Te'eni, 2016). Relying on Norman's (1990) conceptualization of affordance, we explored the range of action possibilities and concerns that health workers expect from the introduction of service robots. Given that health workers perceived these opportunities differently, we found it valuable to use the concept of niches—as envisaged by Gibson (1979) but often overlooked in IS research - to make sense of the relatedness of social, material, and contextual aspects of IT artifacts. Of particular value was understanding that end-user niches are unlikely to be singular or static, since they represent situated shared beliefs, which depend on the sociocultural background and work environment of end-users, and may therefore contradict or compete against other niches. In our view, knowing and understanding these different perceptions (and the reasons for possible contradictions) is important for managing resistance and the susceptibility of various niches in a hospital and for creating managerial awareness of varying demands, needs, and surrounding conditions an IT artifact faces.

However, given the dynamic and relational nature of affordances, as presented in this paper, more deliberations are needed to understand niche evolution concerning different technologies, industries, and organizational contexts. Further research should also explore fundamental assumptions about temporal effects on the adoption, appropriation, and adaptation of emerging technologies in order to create a more solid foundation for theorizing and theory-building. As noted, the continuous observation of dominant and subordinate end-user perceptions could lead to better explanations and predictions of evolutionary changes relating to user behavior, technological tweaks, or environmental remodeling. Keeping an openended view about possible shifts in perceived affordances and niches should also allow for more accurate insights, since the pace of digital innovation is rapid, requiring frequent reconsideration.

Further, with the use of Q-methodology as a means to identify niches, we consciously introduced subjectivity into the research process—-with all its benefits and negatives. 
Finally, we also seek to motivate IS scholars to broadly investigate service robots. The list of both technological and social issues and challenges remains very long indeed (Broadbent et al., 2009). Because service robots-as opposed to industrial robots-are often in much closer contact with humans, the significance of sociocultural problems is even higher. In our view, IS researchers must dig deeper, so as to understand the interplays between material, social, and environmental variables and to provide multidisciplinary and contextually rich solutions.

\section{Acknowledgements}

The authors wish to thank the editors and reviewers of this paper for their insightful comments that have greatly improved its content and presentation. They also want to extend their gratitude to the Swiss Academy of Engineering Sciences and the Swiss Informatics Society for their financial support.

\section{References}

AHN HS, KUO I-H, DATTA C, STAFFORD R, KERSE N, PERI K, BROADBENT E and

MACDONALD BA (2014) Design of a kiosk type healthcare robot system for older people in private and public places. In Simulation, modeling, and programming for autonomous robots (BRUGALI D, BROENINK JF, KROEGER T and MACDONALD BA, Eds.), pp 578-589, Springer, Cham.

AL-NATOUR S and BENBASAT I (2009) The adoption and use of IT artifacts: A new interaction-centric model for the study of user-artifact relationships. Journal of the Association for Information Systems 10(9), 661-685.

ALVES-OLIVEIRA P, PETISCA S, CORREIA F, MAIA N and PAIVA A (2015) Social robots for older adults: Framework of activities for aging in place with robots. In Social robotics (TAPUS A, ANDRÉ E, MARTIN J-C, FERLAND F and AMMI M, Eds.), pp 11-20, Springer, Cham.

BAKER R, WILDMAN J, MASON H and DONALDSON C (2014) Q-ing for health - A new approach to eliciting the public's views on health care resource allocation. Health Economics 23(3), 283-297.

BARENTSEN K and TRETTVIK J (2002) An activitiy theory approach to affordance. Proceedings of the 2nd Nordic Conference on Human-Computer Interaction, Aarhus, Denmark, pp 51-60. 
BARRETT M, OBORN E, ORLIKOWSKI WJ and YATES J (2012) Reconfiguring boundary relations: Robotic innovations in pharmacy work. Organization Science 23(5), 1448-1466.

BATTILANA J, LECA B and BOXENBAUM E (2009) How actors change institutions: Towards a theory of institutional entrepreneurship. The Academy of Management Annals 3(1), 65-107.

BEPKO JR RJ, MOORE JR and COLEMAN JR (2009) Implementation of a pharmacy automation system (robotics) to ensure medication safety at Norwalk hospital. Quality Management in Healthcare 18(2), 103-114.

BERLINGER NT (2006) Robotic surgery — squeezing into tight places. New England Journal of Medicine 354(20), 2099-2101.

BERTELSEN OW (2006) Tertiary artifacts at the interface. In Aesthetic computing (FISHWICK PA, Ed.), pp 357-368, MIT Press, Cambridge, MA.

BEST ML, SMYTH TN, ETHERTON J and WORNYO E (2010) Uses of mobile phones in post-conflict Liberia. Information Technologies \& International Development 6(2), 91-108.

BHATTACHERJEE A and HIKMET N (2007) Physicians' resistance toward healthcare information technology: A theoretical model and empirical test. European Journal of Information Systems Journal 16(6), 725-737.

BODNER J, WYKYPIEL H, WETSCHER G and SCHMID T (2004) First experiences with the da Vinci operating robot in thoracic surgery. European Journal of Cardio-theracic Surgery 25(5), 844-851.

BOUCHARD T (1976) Field research methods: Interviewing, questionnaires, participant observation, systematic observation, unobtrusive measures. In Handbook of industrial and organisational psychology (DUNNETTE M, Ed.), pp 363-413, Rand NcNally, Chicago.

BOUWMAN H, BEJAR A and NIKOU S (2012) Mobile services put in context: A Q-sort analysis. Telematics and Informatics 29(1), 66-81.

BROADBENT E, STAFFORD R and MACDONALD B (2009) Acceptance of healthcare robots for the older population: Review and future directions. International Journal of Social Robotics 1(4), 319-330.

BROWN SR (1993) A primer on Q methodology. Operant Subjectivity 16(3/4), 91-138. 
BYGSTAD B, MUNKVOLD BE and VOLKOFF O (2016) Identifying generative mechanisms through affordances: A framework for critical realist data analysis. Journal of Information Technology 31(1), 83-96.

CEPOLINA FE and MUSCOLO GG (2014) Design of a robot for hygienization of walls in hospital environments. Proceedings of the 41st International Symposium on Robotics, Munich, Germany, pp 1-7.

CHAMERO A (2011) Radical embodied cognitive science. MIT Press, Cambridge, MA.

COOPER RB and ZMUD RW (1990) Information technology implementation research: A technological diffusion approach. Management Science 36(2), 123-139.

COSTALL A (1997) The meaning of things. Social Analysis: The International Journal of Social and Cultural Practice 41(1), 76-85.

CREED WED, DEJORDY R and LOK J (2010) Being the change: Resolving institutional contradiction through identity work. Academy of Management Journal 53(6), 1336-1364.

DAVERN M, SHAFT T and TE'ENI D (2012) Cognition matters: Enduring questions in cognitive is research. Journal of the Association for Information Systems 13(4), 273-314.

DEERY J (1997) Courier robot keeps hospital staff 'on the job. Journal For Healthcare Quality: Official Publication of the National Association for Healthcare Quality 19(1), 22-23.

DEMIR R (2015) Strategic activity as bundled affordances. British Journal of Management 26(S1), S125-S141.

DENNIS KE (1988) Q-methodology: New perspectives on estimating reliability and validity. In Measurement of nursing outcomes (STRICKLAND OL and WALTZ CF, Eds.), pp 409-419, Springer, New York.

DIPROSE JP, PLIMMER B, MACDONALD BA and HOSKING JG (2012) How people naturally describe robot behaviour. Proceedings of the Australasian Conference on Robotics and Automation, Wellington, New Zealand, pp. 1-9.

DONNER J (2004) Microentrepreneurs and mobiles: An exploration of the uses of mobile phones by small business owners in Rwanda. The Massachusetts Institute of Technology Information Technologies and International Development 2(1), 1-21.

DOOLIN B (2004) Power and resistance in the implementation of a medical management information system. Information Systems Journal 14(4), 343-362. 
FARAJ S. and AZAD B (2012) The Materiality of Technology: An Affordance Perspective. In Materiality and Organizing: Social Interaction in a Technological World (LEONARDI PM, NARDI BA and KALLINIKOS J, Eds.), pp 237-258, Oxford University Press, Oxford.

FORBES (2014) Top 20 technologies that will change our lives: Next up - Digital medicine. http://www.forbes.com/sites/reenitadas/2014/07/14/top-20-technologies-that-will-change-ourlives-next-up-digital-medicine/\#8ef5bcef2c9f

GIBSON JJ (1979) The ecological approach to visual perception. Houghton Mifflin, Boston.

GOH JM, GAO G and AGARWAL R (2011) Evolving work routines: Adaptive routinization of information technology in healthcare. Information Systems Research 22(3), 565-585.

GUEST G, BUNCE A and JOHNSON L (2006) How many interviews are enough?: An experiment with data saturation and variability. Field Methods 18(1), 59-82.

HAFERMALZ E, HOVORKA DS and RIEMER K (2015) Shared secret places: Social media and affordances. Proceedings of the 26th Australasian Conference on Information Systems, Adelaide, Australia, pp 111.

HAGELE M (2016) Robots conquer the world [turning point]. IEEE Robotics \& Automation Magazine 23(1), 120-118.

HAIDEGGER T, BARRETO M, GONÇALVES P, HABIBE M, RAGAVANF SKV, LI H, VACCARELLA A, PERRONE R and PRESTES E (2013) Applied ontologies and standards for service robots. Robotics and Autonomous Systems 61(11), 1215-1223.

HEDBERG A and MOROSI M (2015) Keeping health high on the eu agenda: Role for economic governance?, European Policy Centre, Brussels, Belgium.

IDC (2015) Annual IT spending by western european healthcare providers to reach $\$ 14.6$ billion by 2018 . IDC, London.

IIVARI J, ISOMÄKI H and PEKKOLA S (2010) The user - The great unknown of systems development: Reasons, forms, challenges, experiences and intellectual contributions of user involvement. Information Systems Journal 20(2), 109-117. 
INTERNATIONAL FEDERATION OF ROBOTICS (2016) Definition of service robots.

http://www.ifr.org/service-robots/

INTERNATIONAL STANDARDIZATION ORGANIZATION (2016) Robots and robotic devices vocabulary. http://www.iso.org/obp/ui/\#iso:std:iso:8373:ed-2:v1:en:term:2.10

JAYAWARDENA C, KUO IH, BROADBENT E and MACDONALD BA (2014) Socially assistive robot healthbot: Design, implementation, and field trials. IEEE Systems Journal 10(3), 1056-1067.

JOINT INSTITUTE FOR INNOVATION POLICY OF THE EUROPEAN COMMISSION (2012) Investigating in research and innovation for grand challenges. https://ec.europa.eu/research/erab/pdf/erab-study-grand-challanages-2012_en.pdf

KANE GC, FICHMAN RG, GALLAUGHER J and GLASER J (2009) Community relations 2.0. Harvard Business Review, 87 (11), 45-50.

KIM H-W and KANKANHALLI A (2009) Investigating user resistance to information systems implementation: A status quo bias perspective. MIS Quarterly 33(3), 567-582.

KIRSCHLING TE, ROUGH SS and LUDWIG BC (2009) Determining the feasibility of robotic courier medication delivery in a hospital setting. American Journal of Health-System Pharmacy 66(19), 1754-1762.

KLAUS T, WINGREEN SC and BLANTON JE (2010) Resistant groups in enterprise system implementations: A Q-methodology examination. Journal of Information Technology 25(1), 91-106.

KUO IH, RABINDRAN JM, BROADBENT Y, LEE YI, KERSE N, STAFFORD RMQ and MACDONALD BA (2009) Age and gender factors in user acceptance of healthcare robots. Proceedings of the 18th IEEE International Symposium on Robot and Human Interactive Communication, Toyama, Japan, pp 214-219.

LANAMÄKI A, THAPA D and STENDAL K (2016) When is an affordance? Outlining four stances. Proceedings of the IFIP WG 8.2 Working Conference on Information Systems and Organizations, Dublin, Ireland, pp 125-139.

LEONARDI PM (2011) When flexible routines meet flexible technologies: Affordance, constraint, and the imbrication of human and material agencies. MIS Quarterly 35(1), 147-176. 
LEONARDI PM (2013) Theoretical foundations for the study of sociomateriality. Information and Organization 23(2), 59-76.

LI R, WANG S, DENG H, WANG R and CHANG KC (2012) Towards social user profiling: unified and discriminative influence model for inferring home locations. Proceedings of the 18th ACM SIGKDD International Conference on Knowledge Discovery and Data Mining, Bejing, China, pp 1023-1031.

LJUNGBLAD S, KOTRBOVA J, JACOBSSON M, CRAMER H and NIECHWIADOWICZ K (2012) Hospital robot at work: Something alien or an intelligent colleague? Proceedings of the ACM 2012 Conference on Computer Supported Cooperative Work, Seattle, WA, pp 177-186.

MAGNANI L (2008) Chances, affordances, niche construction. In Knowledge-based intelligent information and engineering systems (LOVREK I, HOWLETT RJ and JAIN LC, Eds.), pp 719-726, Springer, Berlin.

MAJCHRZAK A and MARKUS ML (2012) Technology affordances and constraints in management information systems. In Encyclopedia of Management Theory (KESSLER E, Ed.), pp 832-836, Sage, London.

MCKEOWN B and THOMAS D (1988) Q methodology. Sage Publications, Beverly Hills, CA.

MESGARI M and OKOLI C (2015) Ecological approach to user sensemaking of technology. Proceedings of the 36th International Conference on Information Systems, Fort Worth, TX, pp 1-12.

METTLER T and RAPTIS DA (2012) What constitutes the field of health information systems? Fostering a systematic framework and research agenda. Health Informatics Journal 18(2), 147-156.

MIRANI R and LEDERER AL (1998) An instrument for assessing the organizational benefits of is projects. Decision Sciences 29(4), 803-838.

NEJAT G, YIYUAN S and NIES M (2009) Assistive robots in health care settings. Home Health Care Management \& Practice 21(3), 177-187.

NEVO D and WADE MR (2007) How to avoid disappointment by design. Communications of the ACM 50(4), 43-48.

NORMAN DA (1990) The design of everyday things. Doubleday, New York, NY. 
O'LEARY K, WOBBROCK JO and RISKIN EA (2013) Q-methodology as a research and design tool for hci. Proceedings of the SIGCHI Conference on Human Factors in Computing Systems, Paris, France, pp 19411950.

OBORN E, BARRETT M and DARZI A (2011) Robots and service innovation in health care. Journal of Health Services Research \& Policy 16(1), 46-50.

ODLING-SMEE JJ (1988) The role of behavior in evolution. Cambridge University Press, Cambridge, UK.

ORLIKOWSKI WJ and IACONO CS (2001) Research commentary: Desperately seeking the "IT" in IT research—a call to theorizing the IT artifact. Information Systems Research 12(2), 121-134.

OUDSHOORN N and PINCH T (2003) How users matter: The co-construction of users and technology (inside technology). MIT Press, Cambridge, MA.

OZKIL AG, FAN Z, DAWIDS S, AANES H, KRISTENSEN JK and CHRISTENSEN KH (2009) Service robots for hospitals: A case study of transportation tasks in a hospital. Proceedings of the IEEE International Conference on Automation and Logistics, Shenyang, China, pp 289-294.

PATTON MQ (2002) Qualitative research and evaluation methods. Sage Publications, Thousand Oaks, CA.

POULSTON A, STEVENSON M and BONTCHEVA K (2016) User profiling with geo-located posts and demographic data. Proceedings of the 1st Workshop on Natural Language Processing and Computational Social Science, Austin, TX, pp 43-48.

POZZI G, PIGNI F and VITARI C (2014) Affordance theory in the is discipline: A review and synthesis of the literature. Proceedings of the Twentieth Americas Conference on Information Systems, Savannah, GA, pp 112.

PRESTES E, CARBONERA JL, FIORINI SR, JORGE VAM, ABEL M, MADHAVANB R, LOCORO A, GONCALVES P, BARRETO ME, HABIBG M, CHIBANI A, GÉRARD S, AMIRAT Y and SCHLENOFF C (2013) Towards a core ontology for robotics and automation. Robotics and Autonomous Systems 61, 1193-1204.

RAHIM NZA, LALLMAHOMED MZI, IBRAHIM R and RAHMAN AA (2011) A preliminary classification of usage measures in information system acceptance: A Q-sort approach. International Journal of Technology Diffusion 2(4), 25-47. 
RIENER R, LUNENBURGER L, JEZERNIK S, ANDERSCHITZ M, COLOMBO G and DIETZ V

(2005) Patient-cooperative strategies for robot-aided treadmill training: First experimental results. IEEE Transactions on Neural Systems and Rehabilitation Engineering 13(3), 380-394.

SABHERWAL R, JEYARAJ A and CHOWA C (2006) Information system success: Individual and organizational determinants. Management Science 52(12), 1849-1864.

SEIDEL S, RECKER J and VOM BROCKE J (2013) Sensemaking and sustainable practicing: Functional affordances of information systems in green transformations. MIS Quarterly 37(4), 1275-1299.

SERGEEVA A, HUYSMAN M and FARAJ S (2015) Transforming work practices of operating room teams: The case of the Da Vinci robot. Proceedings of the 36th Interational Conference on Information Systems, Fort Worth, USA, pp 1-10.

SHOTTER J (1983) "Duality of structure" and "intentionality" in an ecological psychology. Journal for the Theory of Social Behavior 13(1), 19-44.

STAINTON ROGERS R (1995) Q methodology. In Retbinking methods in psychology (SMITH JA, HARRÉ R and VAN LANGENHOVE L, Eds.), Sage Publications, London.

STEPHENSON W (1986) Protoconcursus: The concourse theory of communication: I. Operant Subjectivity $9(2), 37-58$.

STRAUSS AL and CORBIN J (1998) Basics of qualitative research: Techniques and procedures for developing grounded theory. Sage, Newbury Park.

SWISS FEDERAL STATISTICAL OFFICE (2016) Hospital statistics. Swiss Federal Statistical Office, Neuchâtel, Switzerland.

TAKAYAMA L, JU W and NASS C (2008) Beyond dirty, dangerous and dull: What everyday people think robots should do. Proceedings of the 3rd ACM/IEEE International Conference on Human Robot Interaction, Amsterdam, The Netherlands, pp 25-32.

TEDDLIE C and YU F (2007) Mixed methods sampling: A typology with examples. Journal of Mixed Methods Research 1(1), 77-100.

TE'ENI, D (2016) Contextualization and problematization, gamification and affordance: A traveler's reflections on EJIS. European Journal of Information Systems 25(6), 473-476. 
THE ECONOMIST (2014) New roles for technology: Rise of the robots.

http://www.economist.com/news/leaders/21599762-prepare-robot-invasion-it-will-change-waypeople-think-about-technology-rise

THE WALL STREET JOURNAL (2012) The robots are coming to hospitals.

http://www.wsj.com/news/articles/SB10001424052702304459804577281350525870934

THOMPSON G (1966) The evaluation of public opinion. In Reader in public opinion and communication

(BERELSON B and JANOWITZ M, Eds.), pp 7-12, Free Press, New York.

THRUN S (2004) Toward a framework for human-robot interaction. Human-Computer Interaction 19(1), 9-

24.

TREEM JW and LEONARDI PM (2013) Social media use in organizations: Exploring the affordances of visibility, editability, persistence, and association. In Communication yearbook (SALMON CT, Ed), pp 143-189, Routledge, New York.

TSUI KM, DESAI M, YANCO HA and UHLIK C (2011) Exploring use cases for telepresence robots. In Proceedings of the 6th ACM/IEEE International Conference on Human-Robot Interaction, pp 11-18, Lausanne, Switzerland.

VALENTA AL and WIGGER U (1997) Q-methodology: Definition and application in health care informatics. Journal of the American Medical Informatics Association 4(6), 501-51.

VAN EXEL J and DE GRAAF G (2005) Q methodology: A sneak preview. http://qmethod.org/articles/vanExel.pdf

VOLKOFF O and STRONG DM (2013) Critical realism and affordances: Theorizing it-associated organizational change processes. MIS Quarterly 37(3), 819-834.

WANG C, SAVKIN AV, CLOUT R and NGUYEN HT (2015) An intelligent robotic hospital bed for safe transportation of critical neurosurgery patients along crowded hospital corridors. IEEE Transactions on Neural Systems and Rehabilitation Engineering 23(5), 744-754.

WATTS S and STENNER P (2012) Doing Q methodological research - theory method and interpretation. Sage Publications, London. 
WINGREEN SC, LEROUGE C and BLANTON JE (2009) Structuring training for it professionals and the firm: An application of the q-methodology. International Journal of Global Management Studies 1(1), 5367.

YOO Y, LYYTINEN KJ, BOLAND RJ and BERENTE N (2010) The next wave of digital innovation:

Opportunities and challenges.

\section{Appendix - Interview guide for concourse}

1. What is your role in the hospital?

2. Who is dealing with the organizational development in your hospital?

a. Is a specific organizational unit focusing on organizational development? Do you have an innovation strategy for your hospital?

b. How much money does your hospital spend on organizational development and innovation in the last 5 years?

c. Who would finance inter-organizational projects?

d. Are there external employees involved in decisions regarding the organizational development in your hospital?

3. Do you already have experiences with service robots? Which? If not, did you ever consider introducing robots in your hospital? For which areas or services?

4. What is the status quo regarding the following services (process, process time, volume, frequency, responsibilities, etc.)

a. Meal service (delivery of food and beverages)

b. Medication (dispensing of drugs)

c. Care support (e.g. lifting assistance, therapeutic assistance)

d. Bed linen (delivery of clean, removing of dirty laundry)

e. Cleaning (sterile and non-sterile areas)

f. Beds (allocation and provision of beds)

g. Waste (transportation of regular and contaminated waste)

h. Other transports

5. For which services a service robot would be an option respectively implementable in your hospital? For which services a service robot would not be an option? Why?

6. Which hospital areas would benefit from service robots (e.g. operating room, intensive care, pharmacy, wards, internal logistics, kitchen)? In which way?

7. What would be the advantages for each service robot-supported service?

8. Who would be the main beneficiary of the introduction of the service robot?

9. What would be the disadvantages for each service robot-supported service respectively who would be disadvantaged of the introduction of service robots?

10. Which barriers would inhibit the introduction of service robots for each service?

11. Which measures would be necessary that you would opt for service robots in your hospital?

12. How complex would you rate the introduction of service robots in your hospital (for the different services)?

13. Would you like to test service robots? 
14. Who in your organization ultimately decides if service robots are introduced or not? 